\title{
PERSPECTIVE
}

\section{Amniotic membrane transplantation}

\author{
Harminder S Dua, Augusto Azuara-Blanco
}

In 1910 Davis was the first to report the use of fetal membranes as surgical material in skin transplantation. ${ }^{1}$ Since then the use of amniotic membrane in surgery has been expanded. ${ }^{1-9}$ It is now utilised as a biological dressing for burned skin, skin wounds, and chronic ulcers of the leg, ${ }^{9-16}$ as an adjunctive tissue in surgical reconstruction of artificial vagina, ${ }^{917-19}$ and for repairing omphaloceles. ${ }^{9}{ }^{20} \mathrm{It}$ has also been used to prevent tissue adhesion in surgical procedures of the abdomen, head, and pelvis. ${ }^{921}{ }^{22}$ In the 1940 s several authors reported the beneficial role of amniotic membrane in treating a variety of ocular surface disorders. ${ }^{5-7}{ }^{23}$ However, its use was abandoned for decades until recently, when it was reintroduced to ophthalmologists. Several studies have addressed this subject and the scope of the application of amniotic membrane transplantation (AMT) in the management of ocular surface disorders is ever increasing.

Certain characteristics make the amniotic membrane ideally suited to its application in ocular surface reconstruction. It can be easily obtained and its availability is nearly unlimited. The tissue can be preserved at $-80^{\circ} \mathrm{C}$ for several months, allowing sufficient time to plan surgery or consider a trial of other options. Amniotic membrane does not express HLA-A, B, or DR antigens and hence immunological rejection after its transplantation does not occur. $^{24-26}$ It is also believed to have antimicrobial properties, reducing the risks of postoperative infection. ${ }^{27}$ Antifibroblastic activity ${ }^{28-30}$ and cell migration/growth promoting activity ${ }^{31-33}$ have also been demonstrated with regard to the amniotic membrane.

The purpose of this paper is to review the characteristics of amniotic membrane that make it potentially useful to treat ocular surface abnormalities and to discuss the current indications, the surgical technique, and the outcome of AMT.

\section{Histology and physiology}

Mammalian embryos lie within a fluid filled sac (fetal membranes) that arises from extraembryonic tissues. At full term of gestation, the fetal membranes are composed of two principal layers. The outer layer or chorion which forms the outer aspect of the sac and is in contact with maternal cells. It consists of compressed trophoblastic tissue of chorion laeve and mesenchymal tissue. The inner layer or amniotic membrane consists of a single layer of ectodermally derived columnar cells firmly fixed to an underlying layer of mesenchyme which contains large amounts of collagen. ${ }^{34} 35$ The amniotic membrane is bathed by amniotic fluid. According to Shimazaki et al, ${ }^{31}$ the epithelium of the amniotic membrane survives for up to 70 days after preservation. We have noted that after freezing the amniotic membrane at $-70^{\circ} \mathrm{C}$ for 6 months to a year the epithelial cells appear very vacuolated but remain attached to the underlying basement membrane and mesenchyme (unpublished data).
The apical surface of amniotic cells have many microvilli (Fig 1). At the base, cell processes or pedicels extend into the basement membrane in podocyte fashion. The basal cell processes have a hemidesmosome type of attachment to the basal membrane with tonofilaments, and the subjacent basement membrane substance is partly amorphous and partly microfibrillar. The cytoplasm contains many pinocytic vesicles, abundant organelles including cisternal endoplasmic reticulum, and Golgi apparatus. The nucleus has a very irregular configuration, with a number of indentations of the nuclear membrane. The nucleolus is often large and homogeneous suggesting nucleolar activity. Overall, the ultrastructure of the epithelium suggests that the amnion has multiple specialised functions. It has been specifically adapted to perform three major functions - as a covering epithelium, as an active secretory epithelium, and for intense intercellular and transcellular transport. ${ }^{34}{ }^{35}$

\section{Amniotic membrane in ophthalmology}

MECHANISM OF ACTION

Promoter of epithelialisation

The presence of a normal substrate in the cornea is essential for normal proliferation and differentiation of epithelial cells. Basement membrane facilitates migration of epithelial cells ${ }^{33}{ }^{36}$; it also reinforces adhesion of basal epithelial cells, ${ }^{37}$ promotes epithelial differentiation, ${ }^{38} 39$ and prevents epithelial apoptosis. ${ }^{40}$ The amniotic membrane, by serving as a "transplanted basement membrane", acts as a new healthy substrate suitable for proper epithelialisation. Additionally, the amniotic membrane produces various growth factors such as basic fibroblast growth factor, hepatocyte growth factor, and transforming growth factor $\beta$, that can stimulate epithelialisation. ${ }^{31}{ }^{41}$ However, it has been demonstrated that cryopreservation of amnion results in a decrease of growth factors. ${ }^{41}$ Amniotic membrane also inhibits protease activity. ${ }^{30}{ }^{42}$ It has also been shown that in some instances the amniotic membrane, rather than providing a substrate, acts as a "bandage contact lens" allowing epithelialisation to occur under its cover. ${ }^{43}$

\section{Inhibitor of fibrosis}

Several factors are involved in the antifibrotic effect of the amniotic membrane. ${ }^{28}{ }^{29}$ It has been shown that amniotic membrane induces a downregulation of transforming growth factor $\beta$ signalling, responsible for fibroblastic activation in wound healing. ${ }^{28}$ The amniotic membrane may also function as an anatomical barrier, keeping the potentially adhesive surfaces apart. The stroma of the amniotic membrane is normally avascular and is believed to inhibit the incursion of new vessels.

\section{Indications for AMT in ophthalmology}

Amniotic membrane transplantation has been successfully used in patients with persistent epithelial defects unresponsive to medical treatment, ${ }^{43}{ }^{44}$ and as an alternative to conjunctival flaps, botulinum toxin injection, or tarsor- 


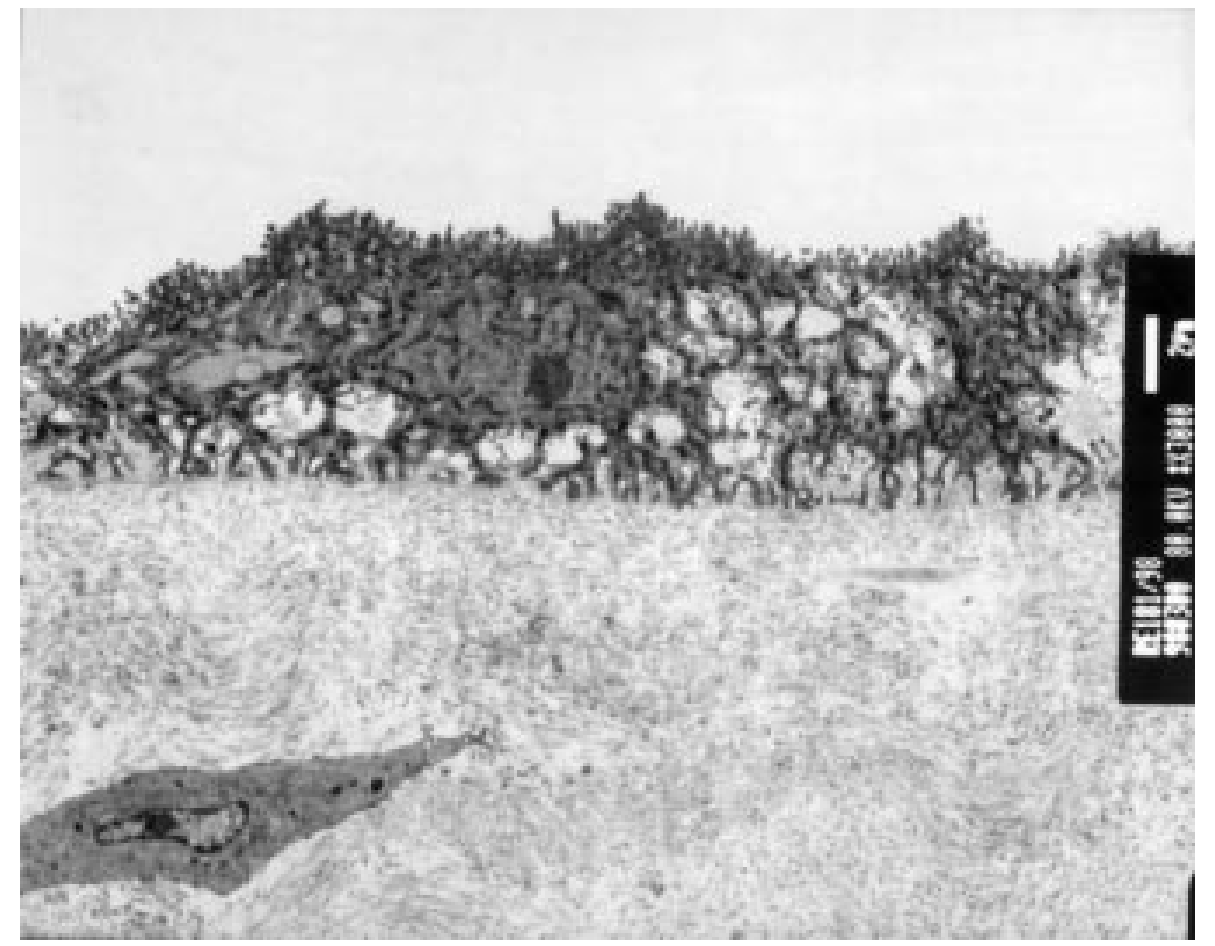

Figure 1 Transmission electron microscopy of the amnion. The apical border of the amniotic epithelial cells contains a great number of microvilli. The cytoplasm contains numerous vesicles. Basal cell processes (pedicels) extend into the basement membrane. The underlying connective tissue has a homogeneous structure.

rhaphy. The frequency of success in two recent series was 10 of 11 cases $^{44}$ and four of five cases, ${ }^{43}$ respectively. In our experience, the amniotic membrane, by virtue of its transparency, allows the patient navigational vision and is particularly useful if the affected eye is the better seeing eye. The use of more than one layer may be effective in covering ulcers with substantial stromal depth. However, the use of AMT as a tectonic procedure in cases with impending or recent perforation appears to be unsatisfactory, and failure was reported in five consecutive cases. ${ }^{43}$

Amniotic membrane has been used as an alternative to conjunctival autograft during the removal of pterygia. The recurrence rate of pterygium after AMT (10.9\% for primary pterygia) was lower than the bare sclera technique $(45 \%)$, but higher than autologous conjunctival graft $(2.6 \%) .^{45}$ Multiple surgical approaches have been used to treat pterygium. Although conjunctival autograft is considered to be the most efficient, AMT appears to be a reasonable option in cases with diffuse conjunctival involvement and patients in whom the bulbar conjunctiva must be preserved for a prospective glaucoma filtering procedure.

AMT has been successfully used in the treatment of recurrent pterygium associated with severe symblepharon and diplopia. ${ }^{31}$ In Shimazaki's series, all four patients had a favourable functional and anatomical outcome after AMT. Similarly, AMT has been used successfully in 13 of 16 eyes in the reconstruction of conjunctival defects created during surgical removal of large conjunctival lesions. ${ }^{33}$

Corneal stem cell deficiency is associated with conjunctivalisation of the cornea and can be complicated with persistent epithelial defects, vascularisation, scarring, calcification, ulceration, melting, and perforation of the cornea. Patients with these abnormalities are poor candidates for conventional corneal transplantation. Lamellar or penetrating keratoplasty provides only a temporary replacement of the host's corneal epithelium and does not permanently restore limbal function. In cases with diffuse corneal stem cell deficiency, limbal transplantation (allo or auto) is now considered essential for corneal surface reconstruction. ${ }^{46-53}$ AMT combined with limbal transplantation has been successfully used in patients with diffuse limbal stem cell deficiency and severe ocular surface disease, including Stevens-Johnson syndrome, advanced ocular cicatricial pemphigoid, chemical and thermal burns. ${ }^{32}{ }^{46}$ Alternatively, autologous limbal-corneal epithelium can be cultured on amniotic membrane and used for corneal surface reconstruction. ${ }^{54}$

Notwithstanding the encouraging and successful results reported thus far it is important to caution against the overenthusiasm in the use of amniotic membranes that is beginning to emerge of late. The beneficial effect of amniotic membrane in the management of ocular surface disorders has not always been validated with controlled clinical trials. In some series the favourable outcomes could well be attributed to concurrent surgical procedures. Shimazaki et $a l^{46}$ stated that "we do not know exactly in which case the amniotic membrane should be used and how much the current procedure (AMT and limbal transplantation) is superior to the simple limbal autograft transplantation." Similarly, Tseng et $a l^{32}$ recently reported successful management of patients with sector limbal stem cell deficiency treated with removal of conjunctiva-like epithelium from the corneal surface combined with AMT. They did not, however, have any controls, where amniotic membrane was not used. In a similar group of patients Dua ${ }^{55}$ and Dua et $a l^{56}$ also reported excellent outcome following removal of conjunctiva-like epithelium, without AMT, suggesting that AMT is probably not required in such patients. Following observations on the healing of corneal epithelial defects involving the limbus, Dua and Forrester ${ }^{57}$ had observed the migration of conjunctival epithelium on to the corneal surface and reported that mechanical debridement could prevent the manifestation of conjunctivalisation of the cornea (partial stem cell deficiency).

Fujishima et al ${ }^{58}$ recently used amniotic membrane in guarded filtration procedures supplemented with mitomycin $\mathrm{C}$ to inhibit scarring and promote filtration. Amniotic membrane was placed underneath the scleral flap. In this 
small series the mid term outcome of trabeculectomy was satisfactory in 13 of 14 eyes. After filtering operations the extraocular changes (that is, subconjunctival fibrosis) account for the majority of failures. Antifibrotic agents, mitomycin $\mathrm{C}$ and 5-fluorouracil, are currently used to improve the chances of success, although the complication rate also rises. ${ }^{59} \mathrm{~A}$ controlled clinical trial will be needed to evaluate whether amniotic membrane helps to improve the outcome of filtration procedures.

Bleb leaks after filtration surgery can be associated with hypotony, shallow flat anterior chamber, and choroidal detachment and may increase the chances for bleb infection and subsequent endophthalmitis. Leaking filtering blebs usually require prompt treatment. Therapeutic options include bandage contact lens, Simmons' shell, injection of autologous blood, cryopexy, thermal Nd:YAG laser, cyanoacrylate glue, fibrin tissue glue, and surgical revision. ${ }^{59}$ Budenz et al ${ }^{60}$ recently reported favourable use of human AMT for revision of leaking blebs after glaucoma surgery in five patients. AMT compared favourably with conjunctival advancement.

Anecdotally, AMT has been successfully used in three patients to treat myopic regression with corneal opacity after photorefractive keratectomy (PRK) in high myopia. ${ }^{61}$ Excessive corneal haze and myopic regression are associated with excessive healing response, which might be inhibited by amniotic membrane. In rabbits the corneal haze was reduced by AMT in excimer laser photoablation..$^{63}$

\section{Surgical principles}

PREPARATION OF AMNIOTIC MEMBRANE

Amniotic membrane is obtained under sterile conditions after elective caesarean delivery from a seronegative donor (see below). Two similar methods of tissue preparation have been described.

(A) Under a lamellar flow hood, the placenta is first washed free of blood clots with balanced saline solution containing $50 \mu \mathrm{g} / \mathrm{ml}$ of penicillin, $50 \mu \mathrm{g} / \mathrm{ml}$ of streptomycin, $100 \mu \mathrm{g} / \mathrm{ml}$ of neomycin, and $2.5 \mu \mathrm{g} / \mathrm{ml}$ of amphotericin $B$. The inner amniotic membrane is separated from the rest of the chorion by blunt dissection (through the potential spaces between these two tissues). The membrane is then flattened onto a nitrocellulose paper, with the epithelium/ basement membrane surface up. The membrane with the paper is cut into $4 \times 4 \mathrm{~cm}$ pieces and placed in a sterile vial containing Dulbecco's modified Eagle's medium and glycerol at a ratio of $1: 1$ ( $\mathrm{vol} / \mathrm{vol})$. The vials are frozen at $-80^{\circ} \mathrm{C}$. The membrane is defrosted immediately before use by warming the container to room temperature for 10 minutes. ${ }^{33}$

(B) After washing with physiological saline or $0.01 \mathrm{M}$ phosphate buffered saline (PBS) containing $100 \mathrm{mg}$ of dibekacin sulphate, the amniotic membrane with the chorion is separated from other uterus tissue by blunt dissection. The membrane is then cut into pieces measuring $5 \times$ $5 \mathrm{~cm}$ and rinsed three times in $0.01 \mathrm{M}$ PBS. Each piece is rinsed in 0.5 M DMSO dissolved in PBS, then in $1.0 \mathrm{M}$ and $1.5 \mathrm{M}$ DMSO in PBS, for 5 minutes each. The membrane is placed in a plastic container and preserved at $-80^{\circ} \mathrm{C}$ until use. The container with amniotic membrane is warmed to room temperature preoperatively, and the membrane is rinsed three times in saline, then once in saline containing $100 \mathrm{mg}$ of dibekacin sulphate. At the time of surgery the amniotic membrane is separated bluntly from the underlying chorion with forceps. ${ }^{53}$

MICROBIOLOGICAL SAFETY

Transmission of infectious agents is one of the risks associated with transplantation of human organs and tissues.
Safety criteria applied to organ transplantation should be applied even more strictly to tissue transplantation such as amniotic membrane. ${ }^{64}$

All recipients of organs and tissues need to be advised that the donors have been tested for some infections, but that there is a very slight possibility that a donor may be infected, for instance, because of the "window period", when the donor is already infected but the screening tests are not yet positive. Where donor tissue can be stored for 180 days without impairing its fitness for use, as is the case with the amniotic membrane, it is considered essential that serological testing of the donor be carried out at the time of procurement and 6 months later, to allow for the window period. Tissue should be used for transplantation only when both samples are negative. This does not, however, exclude the possibility of infection with pathogens for which no test is available such as the Creutzfeldt-Jakob disease (CJD) prion protein. Infection may also occur as a results of procurement procedures and tissue processing. There is therefore a need for microbiological quality control of tissue procurement and any associated banking as well as for prevention of transmission of infection from the donor. ${ }^{64}$

After the identification of a potential donor, a detailed social and medical history needs to be obtained. The clinician responsible for collecting the tissue must ensure that the donor has been asked about any activities or other risk factors which may suggest that the donor is unsuitable. Donors at risk of having HIV (human immunodeficiency virus), $\mathrm{HBV}$ (hepatitis $\mathrm{B}$ virus), $\mathrm{HCV}$ (hepatitis $\mathrm{C}$ virus), and CJD must be excluded. Consent for donation and subsequent use, and for screening for infection must also be obtained at this stage. Local research and ethics committee approval may also be considered necessary in some institutions.

Microbiological testing should be undertaken by laboratories competent to do the tests. Records of tests and results together with serum samples must be kept for 11 years post transplantation and donor anonymity must be maintained. Serum samples from all donors must be tested for anti-HIV-1 and 2, hepatitis B surface antigen (HBsAg), and anti-hepatitis $\mathrm{C}$ virus (anti-HCV). Testing for syphilis is also required. Donors infected with $\mathrm{HIV}-1$ or $2, \mathrm{HCV}$, HBV, or syphilis should be excluded. Testing for cytomegalovirus and toxoplasma is not relevant for most tissue transplantation including amniotic membrane.

Tissue must be handled, processed, and transported at all times in a way that minimises contamination from exogenous sources as far as practically possible. Donor material should be collected under clean and aseptic conditions. When the tissue is stored, a registered medical practitioner must take overall responsibility for the microbiological safety of the tissue and maintenance of records. All tissue must be traceable from the donor via any intermediaries to the recipient and from the recipient back to the donor. ${ }^{64}$

SURGICAL TECHNIQUE

The membrane is always sutured to the ocular surface with its epithelial side up and the mesenchymal surface in contact with the eye, to facilitate adherence of the membrane to the ocular surface. For this reason it is important to be able to distinguish its two surfaces. This is easiest when the membrane is fresh, but when dealing with membranes that have been thawed after storage at $-70^{\circ} \mathrm{C}$ it becomes difficult. Most surgeons have developed a technique that suits them best-for example, mounting the membrane on nitrocellulose paper, the right way up, so that the correct side can be determined when the membrane is thawed. Others will use a suture, with the knot as the marker or 


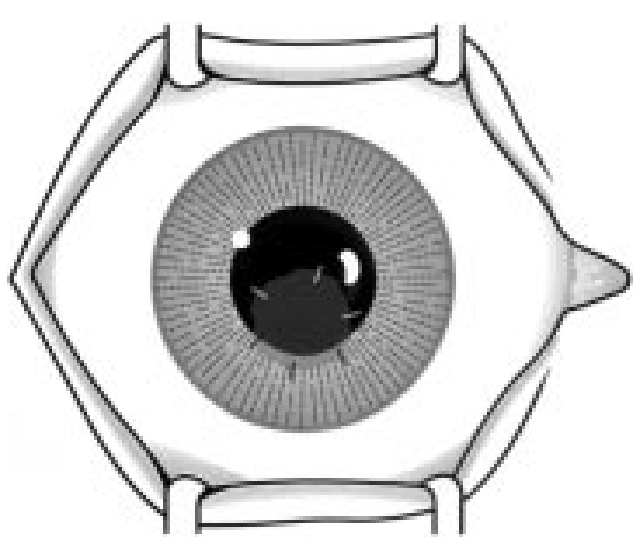

Figure 2 Surgical technique. The diagram illustrates the amniotic membrane sutured to the cornea and covering a paracentral corneal epithelial defect.

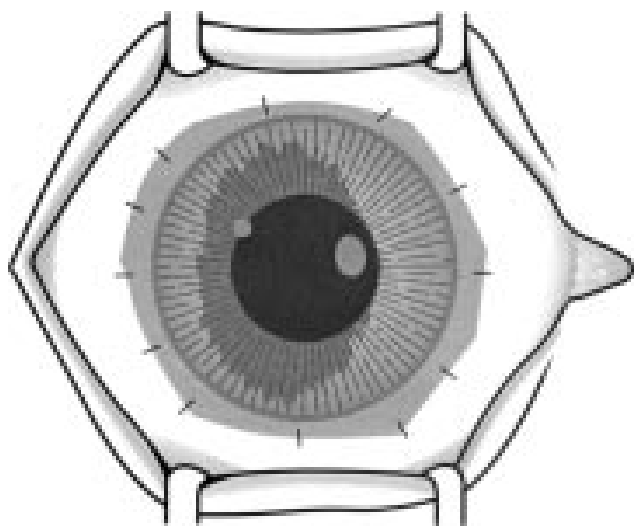

Figure 3 Surgical technique. The amniotic membrane is sutured to perilimbal episclera and to the edge of the conjunctiva (after peritomy) covering the whole corneal surface.

indelible marker pen, to mark one side of the membrane. We have developed a method that we find useful. After spreading the membrane on the ocular surface we apply the tips of a blunt fine forceps to one surface of membrane and pinch lightly with the forceps and lift. A fine strand of "vitreous-like" substance can usually be drawn up from the mesenchymal but not the epithelial (basement membrane) side of the amniotic membrane.

The amniotic membrane is spread on to surface of the eye and cut to appropriate size and shape, keeping the final piece slightly larger than the size of the defect to be covered. It is usually sutured to the cornea with 10-0 Nylon sutures and to the episclera/conjunctiva with 9-0 Vicryl sutures. After surgery a bandage contact lens is put in place, and topical steroids and antibiotics are used. Sutures can be removed at 3 weeks. The membrane stains with fluorescein stain and like the cornea, attracts ciprofloxacin deposits, if the drug is used topically, postoperatively. ${ }^{43}$

In cases of persistent epithelial defects, the base of the ulcer and loose epithelium adjacent to the edge of the ulcer are debrided before applying the membrane. The amniotic membrane is trimmed and fitted to cover the epithelial defect and sutured to the edge of the defect (Fig 2). ${ }^{44}$ If the epithelial defect is large, a 360 degree peritomy is done and the membrane sutured to cover the cornea from limbus to limbus (Fig 3). In pterygium or symblepharon surgery, the membrane is applied to cover areas of conjunctival defects after removal of fibrotic tissue (Fig 4). ${ }^{30}$

Several problems can occur after amniotic membrane transplantation. The amniotic membrane may disintegrate before epithelialisation, in some cases within 2 weeks after transplantation. Necrosis of the amniotic membrane may

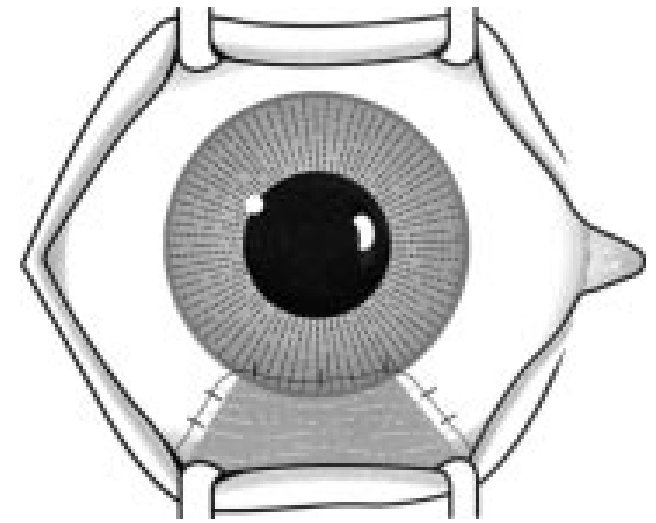

Figure 4 Surgical technique. The amniotic membrane can be used to cover a conjunctival defect after releasing adhesions during symblepharon surgery, and in a similar manner (nasally or temporally) after excision of pterygium.

be related to collagenases present on the ocular surface as, in our experience, it occurs more often in cases with intense inflammation (unpublished data). The amniotic membrane will not remain attached to the ocular surface if the mesenchymal surface is not facing the host.

\section{Summary}

Amniotic membrane has unique properties that can be helpful to treat different ocular surface diseases. AMT is useful in promoting normal epithelialisation of cornea and conjunctiva. It is also effective in preventing excessive fibrosis during ocular surface reconstruction. Future possible indications are being investigated. Because of the potential risk of infection strict safety criteria must be applied. The procedure is still evolving and, not surprisingly, is being tried in a variety of diverse conditions. Some of these may prove inappropriate. Controlled clinical trials will be needed to establish the role of AMT in ocular surface reconstruction.

We are grateful to Vision Express UK Ltd for supporting Dr Azuara-Blanco's fellowship. Dr Azuara-Blanco was the Vision Express fellow in cornea and contact lenses, at the Queen's Medical Centre, University Hospital, Nottingham from July 1997 to December 1998. We are also grateful to April Powell-Richards for her technical assistance.

HARMINDER S DUA

Department of Ophthalmology, University of Nottingham, Queen's Medical Centre, University Hospital, Nottingham

AUGUSTO AZUARA-BLANCO

Department of Ophthalmology, University of Nottingham, Queen's Medical Centre, University Hospital, Nottingham and the Princess Alexandra Eye Pavilion, The Royal Infirmary of Edinburgh,

Edinburgh

1 Davis JW. Skin transplantation with a review of 550 cases at the Johns Hopkins Hospital. fohns Hopkins Med f 1910;15:307.

2 Stern W. The grafting of preserved amniotic membrane to burned and ulcerated skin surfaces substituting skin grafts. $\mathcal{F} A M A$ 1913;13:973-4.

3 Sabella N. Use of fetal membranes in skin grafting. Med Records NY 1913; 83:478-80.

4 Burger K. Artificial vaginal reconstruction with the help of amnios. Zentralblatt Fur Gynakol 1937;2437-40.

5 de Rotth A. Plastic repair of conjunctival defects with fetal membrane. Arch Ophthalmol 1940;23:522-5.

6 Sorsby A, Symmons HM. Amniotic membrane grafts in caustic burns of the eye (burns of second degree). Br f Ophthalmol 1946;30:337-45.

7 Sorsby A, Haythorne J, Reed H. Further experience with amniotic membrane grafts in caustic burns of the eye. Br F Ophthalmol 1947;31:40918.

8 Troensagaard-Hansen E. Amniotic grafts in chronic skin ulceration. Lancet 1950;1:859-60.

9 Trelford JD, Trelford-Sauder M. The amnion in surgery, past and present. Am f Obstet Gynecol 1979;134:844-5.

10 Colocho G, Graham III WP, Green AE, et al. Human amniotic membrane as a physiologic wound dressing. Arch Surg 1974;109:370-3.

11 Faulk WP, Matthews RN, Stevens PJ, et al. Human amnion as an adjunct in

12 Prasad JK, Feller I, Thompson PD. Use of amnion for the treatment of Stevens-Johnsons syndrome. F Trauma 1986;26:945-6.

13 Subrahmanyam M. Amniotic membrane as a cover for microskin grafts. $\mathrm{Br}$ f Plastic Surg 1995;48:477-8. 
14 Gruss JS, Jirsch DW. Human amniotic membrane: a versatile wound dress-

ing. F Can Med Assoc 1978;118:1237-46.
15 Ward DJ, Bennett JP. The long-term results of the use of human amnion in the treatment of leg ulcers. Br F Plastic Surg 1984;37:191-3.

16 Ward DJ, Bennett JP, Burgos H, et al. The healing of chronic venous leg ulcers with prepared human amnion. Br F Plastic Surg 1989;42:463-7.

17 Dhall K. Amnion graft for treatment of congenital absence of the vagina. $\mathrm{Br}$ f Obstet Gynaecol 1984;91:279-82.

18 Georgy MS, Aziz NL. Vaginoplasty using amnion graft: new surgical technique using the laparoscopic transillumination light. 7 Obstet Gynaecol 1996;16:262-4.

19 Nisolle M, Donnez J. Vaginoplasty using amniotic membranes in cases of vaginal agenesis or after vaginectomy. F Gynecol Surg 1992;8:25-30.

20 Gharib M, Ure BM, Klose M. Use of amniotic grafts in the repair of gastroschisis. Pediatr Surg Int 1996;11:96-9.

21 Rennekampff H-O, Dohrman P, Fory R, et al. Evaluation of amniotic membrane as adhesion prophylaxis in a novel surgical gastroschisis model. Invest Surg 1994;7:187-93.

22 Arora M, Jaroudi KA, Hamilton CJCM, et al. Controlled comparison of Interceed and amniotic membrane graft in the prevention of postoperative Interceed and amniotic membrane graft in the prevention of postoperative 1994;55:179-82.

23 Lavery FS. Lime burn of conjunctiva and cornea treated with amnioplastin graft. Trans Ophthalmol Soc UK 1946;66:668.

24 Adinofli M, Akle CA, McColl I, et al. Expression of HLA antigens, $\beta_{2}$-microglobulin and enzymes by human amniotic membrane. Nature 1982;295:325-7.

25 Houlihan JM, Biro PA, Harper HM, et al. The human amniotic membrane is a site of MHC class $1 \mathrm{~b}$ expression: evidence for the expression of HLA-E and HLA-G. F Immunol 1995;154:565-74.

26 Akle CA, Adinolfi M, Welsh KI, et al. Immunogenicity of human amniotic epithelial cells after transplantation into volunteers. Lancet 1981;2:1003-5.

27 Talmi YP, Sigler L, Inge E. Antibacterial properties of human amniotic membranes. Placenta 1991;12:285-8.

28 Tseng SCG, Li D-Q, Ma X. Down-regulation of TGF- $\beta 1, \beta 2, \beta 3$, and TGG- $\beta$ receptor II expression in human corneal fibroblasts by amniotic membrane. Invest Ophthalmol Vis Sci 1998;39:S428.

$29 \mathrm{Li} \mathrm{DW}$, Tseng SCG. Three patterns of cytokine expression potentially involved in epithelial-fibroblast interactions of human ocular surface. $\mathcal{F} \mathrm{Cell}$ involved in epithelial-fibrob.

30 Kim JS, Park SW, Kim JH, et al. Temporary amniotic membrane graft promotes healing and inhibits protease activity in corneal wound induced by alkali burn in rabbits. Invest Ophthalmol Vis Sci 1998;39:S90.

31 Shimazaki J, Shinozaki N, Tsubota K. Transplantation of amniotic membrane and limbal autograft for patients with recurrent pterygium associated with symblepharon. Br F Ophthalmol 1998;82:235-40.

32 Tseng SCG, Prabhasawat P, Barton K, et al. Amniotic membrane transplantation with or without limbal allografts for corneal surface reconstruction in patients with limbal stem cell deficiency. Arch Ophthalmol 1998;116:43141 .

33 Tseng SCG, Prabhasawat P, Lee S-H. Amniotic membrane transplantation for conjunctival surface reconstruction. Am f Ophthalmol 1997;124:76574.

34 Pollard SM, Aye NN, Simmonds EM. Scanning electron microscopic appearance of normal human amnion and umbilical cord at term. $\mathrm{Br} f$ appearance of normal human
Obstet Gynaecol 1976;83:470-7.

35 van Herendael BJ, Oberti C, Brosens I. Microanatomy of the human amniotic membrane: a light microscopic, transmission and scanning microotic membrane: a light microscopic, transmission
scopic study. Am $\mathcal{F}$ Obstet Gynecol 1978;131:872-80.

36 Terranova VP, Lyall RM. Chemotaxis of human gingival epithelial cells to laminin. A mechanism for epithelial cell apical migration. 7 Periodontol 19minin. A mechan

37 Khodadoust AA, Silverstein AM, Kenyon KR, et al. Adhesion of regenerating corneal epithelium. The role of basement membrane. Am f Ophthalmol 1968;65:339-48.

38 Kurpakus MA, Stock EL, Jones JCR. The role of the basement membrane in differential expression of keratin proteins in epithelial cells. Dev Biol 1992;150:243-55.
39 Guo M, Grinnell F. Basement membrane and human epidermal differentiation in vitro. F Invest Dermatol 1989;93:372-8.

40 Boudreau N, Sympson CJ, Werb Z, et al. Suppression of ICE and apoptosis in mammary epithelial cells by extracellular matrix. Science 1995;267:891-

41 Sato H, Shimazaki J, Shimazaki N, et al. Role of growth factors for ocular surface reconstruction after amniotic membrane transplantation. Invest Ophthalmol Vis Sci 1998;39:S428.

$42 \mathrm{Na} \mathrm{BK}$, Hwang JH, Shin EJ, et al. Analysis of human amniotic membrane components as proteinase inhibitors for development of therapeutic agent of recalcitrant keratitis. Invest Ophthalmol Vis Sci 1998;39:S90.

43 Azuara-Blanco A, Pillai CT, Dua HS. Amniotic membrane transplantation for ocular surface reconstruction. Br f Ophthalmol 1999;83:399-402.

44 Lee SH, Tseng SCG. Amniotic membrane transplantation for persistent epithelial defects with ulceration. Am f Ophthalmol 1997;123:303-12.

45 Prabhasawat P, Barton K, Burkett G, et al. Comparison of conjunctival autografts, amniotic membrane grafts, and primary closure for pterygium autografts, amniotic membrane grafts, and

46 Shimazaki J, Yang H-Y, Tsubota K. Amniotic membrane transplantation for ocular surface reconstruction in patients with chemical and thermal burns. Ophthalmology 1997;104:2068-76.

47 Kenyon KR, Tseng SCG. Limbal autograft transplantation for ocular surface disorders. Ophthalmology 1989;96:709-23.

48 Holland EJ, Schwartz GS. The evolution of epithelial transplantation for severe ocular surface disease and a proposed classification system. Cornea 1996;15:549-56

49 Tan DTH, Ficker LA, Buckley RJ. Limbal transplantation. Ophthalmology 1996;103:29-36.

50 Tsai RJF, Tseng SCG. Human allograft limbal transplantation for corneal surface reconstruction. Cornea 1994;13:389-400.

51 Dua HS, Azuara-Blanco A. Allo-limbal transplantation in patients with limbal stem cell deficiency. Br f Ophthalmol 1999;83:414-19.

52 Tsubota K, Satake Y, Ohyama M, et al. Surgical reconstruction of the ocular surface in advanced ocular cicatricial pemphigoid and Stevens-Johnson syndrome. Am f Ophthalmol 1996;122:38-52.

53 Tsubota K, Toda I, Saito H, et al. Reconstruction of the corneal epithelium by limbal allograft transplantation for severe ocular surface disorders. $O p h$ thalmology 1995;102:1486-96.

54 Tsai RJ-F. Corneal surfaces reconstruction by amniotic membrane with cultivated autologous limbo-corneal epithelium. Invest Ophthalmol Vis Sci 1998;39:S429.

55 Dua HS. The conjunctiva in corneal epithelial wound healing. Br $\mathcal{F}$ Ophthalmol 1998;82:1407-11.

56 Dua HS, Gomes JAP, Singh A. Corneal epithelial wound healing. Br f Ophthalmol 1994;78:401-8.

57 Dua HS, Forrester JV. The corneoscleral limbus in human corneal epithelial wound healing. Am f Ophthalmol 1990;110:646-56.

58 Fujishima H, Shimazaki J, Shinozaki N, et al. Trabeculectomy with the use of amniotic membrane for uncontrollable glaucoma. Ophthalmic Surg Lasers 1988;29:428-31.

59 Azuara-Blanco A, Katz LJ. Dysfunctional filtering blebs. Surv Ophthalmol 1998;43:93-126.

60 Budenz DL, Barton K, Tseng SCG. Repair of leaking glaucoma filtering blebs using preserved human amniotic membrane graft. Invest Ophthalmol Vis Sci 1998;39:S941.

61 Hong JW, Kang SM, Kim HJ, et al. The effect of phototherapeutic keratectomy (PTK)-amniotic membrane transplantation (AMT) on myopic regression with corneal opacity after PRK in high myopia. Invest Ophthalmol Vis Sci 1998;39:S354.

62 Wang M, Gray T, Prabhasawat P, et al. Corneal haze is reduced by amniotic membrane matrix in excimer laser photoablation in rabbits. Invest Ophthalmol Vis Sci 1997;38:S405.

63 Choi YS, Kim JY, Wee WR, et al. Application of amniotic membrane on corneal wound healing after excimer laser PRK. Invest Ophthalmol Vis Sci 1997;38:S536.

64 Committee Microbiological Safety of Blood and Tissues for Transplantation. Guidance on the microbiological safety of human tissues and organs used in transplantation. London: Department of Health. 